\title{
Lifestyle Changes, Mental Health, and Health-related Quality of Life in Children Aged 6-7 Years Before and During the COVID-19 Pandemic in South Germany
}

Deborah Kurz ( $\nabla$ deborah.kurz@uni-ulm.de)

University of Ulm https://orcid.org/0000-0002-6934-9257

Stefanie Braig

University of Ulm: Universitat Ulm

Jon Genuneit

Leipzig University: Universitat Leipzig

Dietrich Rothenbacher

University of Ulm: Universitat Ulm

\section{Research article}

Keywords: COVID-19, child health, mental health, quality of life, wellbeing, SDQ, lifestyle changes

Posted Date: September 30th, 2021

DOI: https://doi.org/10.21203/rs.3.rs-934189/v1

License: (c) (i) This work is licensed under a Creative Commons Attribution 4.0 International License. Read Full License

Version of Record: A version of this preprint was published at Child and Adolescent Psychiatry and Mental Health on March 11th, 2022. See the published version at https://doi.org/10.1186/s13034-022-00454-1. 


\section{Abstract}

Background: The measures against the COVID-19 pandemic are challenging for children and parents, and detrimental effects on child health are suggested especially from lock-down measures and school closings.

Methods: We conducted a cross-sectional analysis using a population based longitudinal (birth-) cohort study (SPATZ study) conducted in the South of Germany. Data included all children of the 6- and 7-year follow-up for whom a questionnaire was completed during first grade of school. Consequently, we were able to analyze children being in first grade before the first lockdown in Germany ( $\leq 15^{\text {th }}$ March 2020 ), as well as children being in first grade during the pandemic ( $>15^{\text {th }}$ March 2020). We conducted descriptive statistics and estimated the associations between the two time periods, before and during the pandemic, and various outcomes of child health using multivariable adjusted linear or logistic regression modeling. The analysis was stratified by gender.

Results: Results among $n=362$ children aged six or seven years showed substantially lower mean scores of health-related quality of life (b: -5.5 , $95 \%$ confidence interval (CI): -9.0, -2.0), and higher mean scores in emotional and behavioral difficulties (b: $2.0,95 \% \mathrm{Cl}: 0.2,3.8)$ in girls during vs. before the COVID19 pandemic using multivariable linear regression modeling. In addition, weekly screen-time was increased in boys by 3.5 hours ( $95 \% \mathrm{Cl}$ : $0.6,6.4$ ). We did not find substantial differences in sleep quality, physical activity, and time spent with books, neither in boys nor in girls, however, the limited sample size has to be considered.

Conclusion: Child health (and behavior) of first grade school children is possibly impacted by the COVID-19 pandemic with adverse consequences possibly differing by gender.

\section{Introduction}

The measures against the COVID-19 pandemic including lock-downs, school closings, contact restrictions, limited possibilities for leisure time activities, and parents working from home are challenging for children and parents. Careful assessment of lifestyle and psychological changes related to the pandemic is needed, ${ }^{1-4}$ considering the acute phases of the pandemic as well as the subsequent phase. ${ }^{3}$ This is necessary to better understand possible undesirable consequences, mitigate potential negative effects, and improve return to normalcy. ${ }^{3}$

Based on the limited findings of population-based, observational studies, which are ongoing before and throughout the pandemic, we aimed to describe selected outcomes of mental health, quality of life and lifestyle patterns in children aged six or seven years participating in the Ulm SPATZ Health Study (SPATZ) by means of cross-sectional analysis before and during the pandemic.

\section{Methods}

SPATZ is a population based longitudinal (birth-) cohort study conducted in Ulm in the South of Germany (overall response 49\%) which started recruitment of newborns and their mothers during hospitalization after delivery in the Department of Gynecology and Obstetrics, University Medical Center Ulm, Ulm year 2012 (which was the only clinic to give birth to a child in Ulm at this time). Details are described elsewhere. ${ }^{5}$ Ethical approval was obtained from the ethics board of Ulm University (no. 311/11).

Data included all children of the 6- and 7-year follow-up of SPATZ for whom a questionnaire was completed during first grade of school. Consequently, we were able to analyze children being in first grade before the first lockdown in Germany ( $\leq 15$ th March 2020), as well as children being in first grade during the pandemic (> 15th March 2020) (notably, schools closed at 16th March 2020) in a cross-sectional manner. Figure 1 shows how the study sample of first-grade school-children (so called "first-grader") was derived from the longitudinal SPATZ cohort study. In detail, four different groups of first-grader were created which came, as mentioned above, from two different follow-up waves. Namely, group 1 from the 8 th wave, and groups $2-4$ from the 9 th wave. The study sample was divided by year of school enrollment based on date of birth. (The reason is, that the initial recruitment for the birth cohort was stretched over a one year time window (13 months from April 2012 to May 2013)). For further explanation, see Fig. 1. All observations in this analysis are independent; only one timepoint of assessment is included for each child.

The main outcome variables of interest were parental reports of children's health-related quality of life (KINDL-R $\mathrm{R}^{6,7}$; higher score = higher quality of life), emotional and behavioral difficulties $\left(\mathrm{SDQ}^{8}\right.$; higher score = more difficulties), physical activity (Bayer ${ }^{9}$; higher score = more physical active), screen-time, time spent with books, and sleep quality (CSHQ ${ }^{10}$; higher score = lower sleep quality). All used questionnaires are validated, except for screen-time, and time spent with books. Though, categories were similar to those used in a large German population-based study (KIGGS). ${ }^{11}$

We conducted descriptive statistics and estimated the associations between the two time periods, before and during the pandemic, and various outcomes of child health using multivariable linear or logistic adjusted regression modeling. The analysis was stratified by gender and adjusted for age, and year of school enrollment (in order to account for the different groups of first-graders), and duration of school education of mother (educational attainment). The latter one was used as a proxy for socio economic status (SES). The analyses were performed using SAS $\AA^{9.4}$ (The SAS Institute, Cary, NC, USA).

\section{Results}

We analyzed data of $n=362$ children; Table 1 shows the descriptive results of the study sample. $52.5 \%(n=190)$ of the study sample were girls, and most of the first-graders $(85.6 \%)$ were 7 years old. $93.9 \%(n=340)$ had a mother with German nationality. The majority of first-graders $(70.7 \%)$ had a mother with high educational attainment ( $\geq 12$ years). Roughly the half of first-graders were enrolled in $2018(46.7 \%, n=169)$, and the others in $2019(53.3 \%, n=193)$. 17.7\% ( $n$ $=64$ ) of all first-graders were in first grade of school during the pandemic (girls $n=32$, and boys $n=32$ ). 
Table 1 shows also, that maternal nationality (German/non-German), maternal educational attainment, age of child (6/7), year of school enrollment (2018/2019), and time of first-grade (before/during the pandemic) were almost equally distributed between boys and girls.

Table 2 shows the distribution of the before mentioned variables within the four different groups of first-graders. Maternal nationality (German/non-German) and children's gender were also almost equally distributed in the different groups of first-graders. Furthermore, descriptive statistics (means and standard deviations) of all analyzed outcomes differed across the groups of first-graders and gender (Table 2).

Comparing the descriptive results of the three groups before the pandemic (group 1-3), 6-year old first-grader (group 1) showed in several outcomes lower scores then the 7-year old first-grader (groups 2, and 3). The group of first-grader during pandemic (group 4) achieved lower scores in many domains of healthrelated quality of life compared to same-aged first-grader before the pandemic (group 2-3). The same pattern was found for SDQ.

Descriptive results for the domain 'physical well-being' showed in boys higher values during the pandemic than before the pandemic (mean (SD): 88.9 (9.5) vs. 87.9 (10.7), 86.3 (12.0). 75.8 (15.9)). Screen-time was highest in first-grader during the pandemic (group 4) compared to same aged first-grader before the pandemic (group 2-3) (Table 2).

Linear regression modelling showed statistically significant lower mean scores of health-related quality of life among girls during vs. before the COVID-19 pandemic (b: -5.5, 95\% confidence interval (CI): -9.0,-2.0) (Table 3). Similar results were found for emotional and behavioral difficulties: Mean SDQ-scores increased in girls by 2.0 points $(95 \% \mathrm{Cl}: 0.2,3.8)$. There were no significant differences in physical activity, time spent with books, and sleep quality during vs. before the pandemic. Notably, the only substantial effect in boys was increased weekly screen-time by 3.5 hours per week (95\% Cl: $0.6,6.4)$.

\section{Discussion}

Our results showed that child health (and behavior) of first grade school children is possibly impacted by the COVID-19 pandemic with adverse consequences differing by gender. In particular, we found short-term differences in mental health in girls, whereas in boys mental health did not appear to be negatively affected in the short term (i.e. no statistical significant difference on scores of KINDL-R and SDQ); however, the limited sample size has to be considered. Our results, based on data collected with the same setting before and during the pandemic in first-graders, showing decreased mental health during the pandemic are in line with several other studies. ${ }^{2,12,13}$ For example, Ravens-Sieberer et al. found also that children and adolescents experienced more mental health problems and higher anxiety levels during the COVID-19 pandemic (compared to data from a representative longitudinal cohort study conducted in Germany before the pandemic). ${ }^{2}$ Further results from Vogel et al., investigating data from Germany, and Luijten et al., investigating data from the Netherlands, also found decreased mental health in children and adolescents during the pandemic. ${ }^{12,13}$

Our study showed different results for boys and girls. Girls were substantially more affected in mental health, whereas boys showed vastly increased screentime. The indicated gender-differences in being adversely affected by the pandemic, especially the detrimental possible effects on girl's mental health are strengthened by other findings. For example, a study conducted under boys and girls in Norway revealed that girls are more affected by the pandemic and more concerned to become infected with the SARS-COV-2 virus than boys. ${ }^{14}$ Also Zhou et al. found that in Chinese adolescents girls were at higher risk for depressive and anxiety symptoms during the pandemic. ${ }^{15}$ Further underpinned by results from Schmidt et al. revealing female gender as a main factor to be more affected. ${ }^{16}$ Hence, further evaluation of gender-specific short-term and long-term pandemic effects is highly warranted.

Although expected and in contrast to previous results, 2,12,17,18 the adverse consequences found do not largely differ according to socioeconomic status (SES): educational attainment of the mother was (only) significantly associated with emotional and behavioral difficulties in boys (data not shown). A previous nationwide study from Germany revealed that children from families with low SES, limited living space, or migration background have been more affected by the pandemic. ${ }^{2}$ Furthermore, living situations and family compositions (e.g. single-parent family, having three or more children) have also been shown to be associated with more adverse mental and social health consequences during the pandemic. ${ }^{13}$ Our contrasting results may be explained by the smaller portion of mothers with low SES in our study with limited statistical power to uncover differences across SES levels.

There were also domains where we did not find substantial differences during vs. before the pandemic neither in boys nor in girls: physical activity, quality of sleep, and time spent with books. Those findings are somewhat in discrepancy to those of Vogel et al. who found that during the pandemic physical activity decreased in children and adolescents aged 9 to 18 years, with stronger differences in children with medium/low SES. ${ }^{12}$ Notably, the children were considerably older compared to our study. Contrary, Poulain et al. found that in 10-year-old German children playing outside increased while the lock-down was ongoing, regardless of SES. ${ }^{19}$ (Authors assessed two time-points during lock-down, one month apart). ${ }^{19}$ Age, as well as the different methodology might have contributed to the diverging results. Nevertheless, the descriptive results of the domain 'physical well-being' of the health-related quality of life questionnaire (KINDL-R) showed for boys higher physical-wellbeing during the pandemic compared to the three groups of first-grader before the pandemic. Those results are only descriptive, however would, if found statistically significant, underpin the results from Poulain et al. Despite the contrary evidence currently available ${ }^{12,19-21}$, it is of high need to further investigate changes in physical activity related to a lockdown/pandemic, as the impact of reduced physical activity and prolonged sedentary behavior is related to several negative health outcomes ${ }^{20,22,23}$ as well as academic achievements. ${ }^{24}$

Our result regarding increased media use in boys by 3.5 hours per week is strengthened by other evidence, which strongly indicates that screen-time substantially raised during the lockdwon. ${ }^{12,19,25}$ An even stronger boost was found in older children. ${ }^{25}$ Vogel et al. found that before the pandemic media use was different between weekends and weekdays (odds ratio (OR) 3.77, $p<0.001$ ), whereas during pandemic it was found to be not. ${ }^{12}$ Comparing weekdays during the pandemic to weekdays before the pandemic, media use (TV/DVD/video) increased by an OR of 3.80 ( $p<0.001) .{ }^{12}$ Meaning, TV/DVD/video consumption at weekdays/weekends during the pandemic was similar to media use at weekends before the pandemic. ${ }^{12}$ Poulain et al. found that during the pandemic higher media use was associated with lower SES. ${ }^{19}$ In our study, SES was not associated with media use. However, the relatively low number of

Page 3/10 
families with a low SES in our study has to be considered. From a public health perspective it is of high need to further evaluate the changes in the totally amount of screen-time under children. ${ }^{26}$

There are limited studies assessing sleep quality in elementary school students during the pandemic. Findings from a survey in Italy revealed, that sleeping patterns changed in all age-groups $\left(1-3,4-5,6-12\right.$, and $13-18$ years) and sleep disorders increased during the lockdown. ${ }^{25}$ Also Lokandwala et al. found changes in sleeping patterns during the pandemic. ${ }^{27}$ The reason for the discrepancy between our findings (no changes in sleep quality) and the existing reports may lie in different methodology used. However, it has to be noted that the determinants of children's sleep behavior are scarcely understood, with moderate evidence for screen-time. ${ }^{4,28}$

Consequently, it is important to recognize the need of fit-for-purpose measurements and measures increasing child health (i) during the long phase out of the pandemic, (ii) during future pandemics, as well as (iii) to be prepared for future pandemics, as it was shown that pre-pandemic behaviors predict duringpandemic behaviors. ${ }^{29}$ Whether gender-specific measures are indicated requires further assessment and corroboration in larger samples.

Our study has limitations: Interpretation of our results was limited by sample size. In addition we had a high proportion of families with high SES at study entry which is representative for the local population, but in the families with low SES and migration background loss to follow up was higher, especially during the first year of follow-up. Also the fact that assessing the impact of COVID-19 pandemic on child health was not an a-priori hypothesis of the Ulm SPATZ Health Study, has to be taken into account. In addition, we lacked specifically generated data on possible effects of the COVID-19 pandemic, meaning we only had the routinely collected study data and no special pandemic related questionnaires, which prevented us from exploring causality and behavioral patterns relating to short-term impact of the COVID-19 pandemic on child health. On the other hand, exactly this could be a strength of the longitudinal SPATZ study, as it is not an intended COVID-19 pandemic-related study, hence preventing several forms of bias, arising from selection and awareness in participants. Meaning, especially for possible pandemic-effects, selection bias, recall bias, and conscious bias, respectively cognitive bias can be minimized when routinely assessed data is used.

Further investigations could account for previous/existing mental health problems in children and parents, as it was shown that especially vulnerable groups suffer more under the pandemic and that parents mental health during the pandemic was related to the child-SDQ-scores. ${ }^{30}$ This could shed light on the intended hypothesis, that supporting parent's mental health might also be helpful for protecting children's mental health. Further analyses should also take data for living-situations and family compositions into account.

Since we analyzed cross-sectional all first grade school children in the SPATZ study, a further longitudinal investigation (taking the above mentioned data into account) is highly warranted. Hence, trajectories of three different points in time (e.g. three waves of a longitudinal cohort study of which one wave would be during the pandemic) could bring more clarity about the possible causal effects of the COVID-19 pandemic on children's mental health and lifestyle changes.

Despite the above-mentioned limitations we conclude that the health (and behavior) of first grade school children may be impacted by the COVID-19 pandemic with adverse consequences possibly differing by gender. Particularly, health-related quality of life, and emotional and behavioral difficulties were worse in girls, and screen-time was higher in boys during vs. before the pandemic.

\section{Abbreviations}

SPATZ - Ulm SPATZ Health Study; OR - odds ratio; Cl - confidence interval; SD - standard deviation, PA - physical activity, SDQ - Strengths and Difficulties Questionnaire, CSHQ - Child Sleep Habits Questionnaire, vs - versus, SES - socio-economic-status, h - hours

\section{Declarations}

\section{Ethics approval and consent to participate:}

Ethical approval was obtained from the ethics board of Ulm University (no. 311/11).

\section{Consent for publication:}

n.a.

\section{Availability of data and material:}

The datasets generated during and/or analyzed during the current study are not publicly available due to ethical restrictions regarding data protection issues and the study-specific consent text and procedure, but anonymized data are available from the corresponding author on reasonable request. Supplemental results on all variables included in the multivariable regression analysis are available upon request.

\section{Competing Interest:}

None of the authors have conflicts of interest with regard to the content of this manuscript.

\section{Funding Sources:}

The Ulm SPATZ Health Study was funded through an unrestricted grant by the Medical Faculty of Ulm University, Ulm, Germany. These funders had no role in the study design; in the collection, analysis, and interpretation of data; in the writing of the report; or in the decision to submit the article for publication. The 
contributing researchers are independent of the funders.

\section{Financial Disclosure:}

None of the authors have financial relationships to disclose.

\section{Contributor's statement:}

Deborah Kurz contributed to the study design and data collection, conceptualized and carried out the statistical analysis, interpreted the data, and wrote the manuscript.

Dietrich Rothenbacher conceived the Ulm SPATZ Health Study, and contributed to recruitment and data collection, critically reviewed and revised the statistical analysis and the manuscript, and approved the final manuscript as submitted.

Jon Genuneit conceived the Ulm SPATZ Health Study and contributed to recruitment and data collection, critically reviewed and revised the statistical analysis and the manuscript, and approved the final manuscript as submitted.

Stefanie Braig revised the interpretation of the statistical analysis, and reviewed and revised the manuscript.

All authors approved the final manuscript as submitted and agree to be accountable for all aspects of the work.

\section{References}

1. Stanton R, To QG, Khalesi S, et al. Depression, Anxiety and Stress during COVID-19: Associations with Changes in Physical Activity, Sleep, Tobacco and Alcohol Use in Australian Adults. Int J Environ Res Public Health. 2020;17(11):4065. doi:10.3390/ijerph17114065

2. Ravens-Sieberer U, Kaman A, Erhart M, Devine J, Schlack R, Otto C. Impact of the COVID-19 pandemic on quality of life and mental health in children and adolescents in Germany. Eur Child Adolesc Psychiatry. Published online January 25, 2021:1-11. doi:10.1007/s00787-021-01726-5

3. Fegert JM, Vitiello B, Plener PL, Clemens V. Challenges and burden of the Coronavirus 2019 (COVID-19) pandemic for child and adolescent mental health: a narrative review to highlight clinical and research needs in the acute phase and the long return to normality. Child Adolesc Psychiatry Ment Health. 2020;14(1):20. doi:10.1186/s13034-020-00329-3

4. Bates L, Zieff G, Stanford K, et al. COVID-19 Impact on Behaviors across the 24-Hour Day in Children and Adolescents: Physical Activity, Sedentary Behavior, and Sleep. Children. 2020;7(9):138. doi:10.3390/children7090138

5. Logan C, Zittel T, Striebel S, et al. Changing Societal and Lifestyle Factors and Breastfeeding Patterns Over Time. PEDIATRICS. 2016;137(5):e20154473e20154473. doi:10.1542/peds.2015-4473

6. Ravens-Sieberer U, Bullinger M. Assessing health-related quality of life in chronically ill children with the German KINDL: first psychometric and content analytical results. Qual Life Res. 1998;7(5):399-407. doi:10.1023/A:1008853819715

7. the BELLA Study Group, Bullinger M, Brütt AL, Erhart M, Ravens-Sieberer U. Psychometric properties of the KINDL-R questionnaire: results of the BELLA study. Eur Child Adolesc Psychiatry. 2008;17(S1):125-132. doi:10.1007/s00787-008-1014-z

8. Goodman R. The Strengths and Difficulties Questionnaire: A Research Note. J Child Psychol Psychiatry. 1997;38(5):581-586. doi:10.1111/j.14697610.1997.tb01545.x

9. Bayer O, Jarczok M, Fischer J, von Kries R, De Bock F. Validation and extension of a simple questionnaire to assess physical activity in pre-school children. Public Health Nutr. 2012;15(9):1611-1619. doi:10.1017/S1368980012001243

10. Owens JA, Spirito A, McGuinn M. The Children's Sleep Habits Questionnaire (CSHQ): psychometric properties of a survey instrument for school-aged children. Sleep. 2000;23(8):1043-1051.

11. Lampert T, Sygusch R, Schlack R. Nutzung elektronischer Medien im Jugendalter: Ergebnisse des Kinder- und Jugendgesundheitssurveys (KiGGS). Bundesgesundheitsblatt - Gesundheitsforschung - Gesundheitsschutz. 2007;50(5-6):643-652. doi:10.1007/s00103-007-0225-7

12. Vogel M, Meigen C, Sobek C, et al. Well-being and COVID-19-related worries of German children and adolescents: A longitudinal study from pre-COVID to the end of lockdown in Spring 2020. JCPP Adv. 2021;1(1). doi:10.1111/jcv2.12004

13. Luijten MAJ, van Muilekom MM, Teela L, et al. The impact of lockdown during the COVID-19 pandemic on mental and social health of children and adolescents. Qual Life Res. Published online May 15, 2021. doi:10.1007/s11136-021-02861-x

14. Kaiser S, Kyrrestad H, Martinussen M. Adolescents' experiences of the information they received about the coronavirus (Covid-19) in Norway: a crosssectional study. Child Adolesc Psychiatry Ment Health. 2021;15(1):30. doi:10.1186/s13034-021-00384-4

15. Zhou S-J, Zhang L-G, Wang L-L, et al. Prevalence and socio-demographic correlates of psychological health problems in Chinese adolescents during the outbreak of COVID-19. Eur Child Adolesc Psychiatry. 2020;29(6):749-758. doi:10.1007/s00787-020-01541-4

16. Schmidt SJ, Barblan LP, Lory I, Landolt MA. Age-related effects of the COVID-19 pandemic on mental health of children and adolescents. Eur J Psychotraumatology. 2021;12(1):1901407. doi:10.1080/20008198.2021.1901407

17. Christner N, Essler S, Hazzam A, Paulus M. Children's psychological well-being and problem behavior during the COVID-19 pandemic: An online study during the lockdown period in Germany. Slobodskaya HR, ed. PLOS ONE. 2021;16(6):e0253473. doi:10.1371/journal.pone.0253473

18. Li W, Wang Z, Wang G, et al. Socioeconomic inequality in child mental health during the COVID-19 pandemic: First evidence from China. $J$ Affect Disord. 2021;287:8-14. doi:10.1016/j.jad.2021.03.009

Page 5/10 
19. Poulain T, Meigen C, Sobek C, et al. Loss of childcare and classroom teaching during the Covid-19-related lockdown in spring 2020: A longitudinal study on consequences on leisure behavior and schoolwork at home. Annunziato RA, ed. PLOS ONE. 2021;16(3):e0247949. doi:10.1371/journal.pone.0247949

20. Xiang M, Zhang Z, Kuwahara K. Impact of COVID-19 pandemic on children and adolescents' lifestyle behavior larger than expected. Prog Cardiovasc Dis. 2020;63(4):531-532. doi:10.1016/j.pcad.2020.04.013

21. Tulchin-Francis K, Stevens W, Gu X, et al. The impact of the coronavirus disease 2019 pandemic on physical activity in U.S. children. J Sport Health Sci. 2021;10(3):323-332. doi:10.1016/j.jshs.2021.02.005

22. Korczak DJ, Madigan S, Colasanto M. Children's Physical Activity and Depression: A Meta-analysis. Pediatrics. 2017;139(4):e20162266. doi:10.1542/peds.2016-2266

23. Chaput J-P, Willumsen J, Bull F, et al. 2020 WHO guidelines on physical activity and sedentary behaviour for children and adolescents aged 5-17 years: summary of the evidence. Int J Behav Nutr Phys Act. 2020;17(1):141. doi:10.1186/s12966-020-01037-z

24. Haapala EA, Väistö J, Lintu N, et al. Physical activity and sedentary time in relation to academic achievement in children. J Sci Med Sport. 2017;20(6):583589. doi:10.1016/j.jsams.2016.11.003

25. Bruni O, Malorgio E, Doria M, et al. Changes in sleep patterns and disturbances in children and adolescents in Italy during the Covid-19 outbreak. Sleep Med. Published online February 2021:S1389945721000940. doi:10.1016/j.sleep.2021.02.003

26. Fang K, Mu M, Liu K, He Y. Screen time and childhood overweight/obesity: A systematic review and meta-analysis. Child Care Health Dev. 2019;45(5):744753. doi:10.1111/cch.12701

27. Lokhandwala S, Holmes JF, Mason GM, et al. Sleep and Coping in Early Childhood During the COVID-19 Pandemic. Front Pediatr. 2021;9:716608. doi:10.3389/fped.2021.716608

28. Belmon LS, van Stralen MM, Busch V, Harmsen IA, Chinapaw MJM. What are the determinants of children's sleep behavior? A systematic review of longitudinal studies. Sleep Med Rev. 2019;43:60-70. doi:10.1016/j.smrv.2018.09.007

29. Wunsch K, Nigg C, Niessner C, et al. The Impact of COVID-19 on the Interrelation of Physical Activity, Screen Time and Health-Related Quality of Life in Children and Adolescents in Germany: Results of the Motorik-Modul Study. Child Basel Switz. 2021;8(2). doi:10.3390/children8020098

30. Adegboye D, Williams F, Collishaw S, et al. Understanding why the COVID-19 pandemic-related lockdown increases mental health difficulties in vulnerable young children. JCPP Adv. 2021;1(1). doi:10.1111/jcv2.12005

\section{Tables}

Table 1 Characteristics of the study sample $(n=362$ children $)$.

\begin{tabular}{|c|c|c|c|}
\hline & Male & Female & Total \\
\hline $\mathbf{N}(\%)$ & $172(47.5)$ & $190(52.5)$ & 362 \\
\hline \multicolumn{4}{|l|}{ Age (years), N (\%) } \\
\hline 6 years & $26(15.1)$ & $26(13.7)$ & $52(14.4)$ \\
\hline 7 years & $146(84.9)$ & $164(86.3)$ & $310(85.6)$ \\
\hline \multicolumn{4}{|l|}{ Nationality mother, N (\%) } \\
\hline German & $159(92.4)$ & $181(95.3)$ & $340(93.9)$ \\
\hline Other & $13(7.6)$ & $9(4.7)$ & $22(6.1)$ \\
\hline \multicolumn{4}{|l|}{ Years of school education mother, N (\%) } \\
\hline$\leq 9$ & $9(5.2)$ & $4(2.1)$ & $13(3.6)$ \\
\hline 10 to 11 & $38(22.1)$ & $53(27.9)$ & $91(25.1)$ \\
\hline$\geq 12$ & $123(71.5)$ & $133(70.0)$ & $256(70.7)$ \\
\hline Missing & $2(1.2)$ & - & $2(0.6)$ \\
\hline \multicolumn{4}{|l|}{ School enrollment of child, $N(\%)$} \\
\hline 2018 & $82(47.7)$ & $87(45.8)$ & $169(46.7)$ \\
\hline 2019 & $90(52.3)$ & $103(54.2)$ & $193(53.3)$ \\
\hline \multicolumn{4}{|l|}{ Time of fist-grade } \\
\hline First-grade during pandemic, $\mathrm{N}(\%)$ & $32(18.6)$ & $32(16.8)$ & $64(17.7)$ \\
\hline First-grade before pandemic, $\mathrm{N}(\%)$ & $140(81.4)$ & $158(83.2)$ & $298(82.3)$ \\
\hline
\end{tabular}


Table 2

Descriptive results of several health related outcomes in $n=362$ children in first grade of school, before and during COVID-19 pandemic, stratified by gender.

\section{COVID-19 pandemic}

\section{Groups}

N

Age (years)

School enrollment

Girls, N (\%)

Nationality mother, $\mathrm{N}(\%)$

German

Other

Years of school education mother, $\mathrm{N}(\%)$

$\leq 9$

10 to 11

$\geq 12$

missing

Characteristics of child health

Health-related quality

of life ${ }^{\mathrm{a}}$, mean (SD)

Girls

Boys

School

Girls

Boys

Social contacts

Girls

Boys

Family

Girls

Boys

Self-esteem

Girls

Boys

Physical well-being
Before the pandemic (until 15th March 2020)
1

52

6

2018

$26(50 \%)$

$50(96.1)$

2 (3.9)

$2(3.9)$

10 (19.2)

39 (75.0)

$1(1.9)$

N
2

117

7

2018

$61(52.1 \%)$

$111(94.9)$

$6(5.1)$

$3(2.6)$

35 (29.9)

$79(67.5)$

N
During the pandemic

4

64

7

2019

$32(50 \%)$

$71(55 \%)$

$122(94.6)$

$57(89.1)$

$7(5.4)$

$7(10.9)$

5 (7.8)

$18(28.1)$

$40(62.5)$

1 (1.6)

N N

$\begin{array}{ll}3(2.3) & 5(7.8) \\ 28(21.7) & 18(28.1) \\ 98(76.0) & 40(62.5) \\ - & 1(1.6) \\ \mathrm{N} & \mathrm{N}\end{array}$

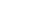




\begin{tabular}{|c|c|c|c|c|c|c|c|c|}
\hline \multirow{2}{*}{$\begin{array}{l}\text { COVID-19 pandemic } \\
\text { Girls }\end{array}$} & \multicolumn{6}{|c|}{ Before the pandemic (until 15th March 2020) } & \multicolumn{2}{|c|}{ During the pandemic } \\
\hline & 23 & $83.7(12.0)$ & 61 & $85.3(13.0)$ & 71 & $89.5(11.1)$ & 29 & $85.3(9.8)$ \\
\hline Boys & 24 & $75.8(15.9)$ & 56 & $86.3(12.0)$ & 58 & $87.9(10.7)$ & 32 & $88.9(9.5)$ \\
\hline \multicolumn{9}{|l|}{ Emotional well-being } \\
\hline Girls & 23 & $85.3(11.1)$ & 61 & $85.6(11.0)$ & 71 & $86.8(10.1)$ & 30 & $84.2(8.9)$ \\
\hline Boys & 24 & $79.7(14.5)$ & 56 & $85.3(13.4)$ & 58 & $85.3(13.6)$ & 32 & $83.2(12.3)$ \\
\hline \multicolumn{9}{|c|}{ Emotional and behavioral difficulties ${ }^{b}$, mean (SD) } \\
\hline Girls & 26 & $7.0(6.0)$ & 61 & $6.0(3.8)$ & 71 & $5.0(3.6)$ & 32 & $7.0(5.3)$ \\
\hline Boys & 26 & $10.0(7.5)$ & 56 & $7.4(4.6)$ & 58 & $6.0(5.2)$ & 32 & $7.9(5.7)$ \\
\hline \multicolumn{9}{|l|}{ PA-Score ${ }^{\mathrm{C}}$ mean (SD) } \\
\hline Girls & 26 & $0.9(3.1)$ & 61 & $1.9(3.0)$ & 71 & $1.4(3.1)$ & 32 & $1.8(2.4)$ \\
\hline Boys & 26 & $0.9(2.7)$ & 56 & $1.9(2.9)$ & 58 & $1.5(2.9)$ & 32 & $1.9(3.3)$ \\
\hline \multicolumn{9}{|c|}{ Physical Inactive ${ }^{\mathrm{d}}, \mathrm{N}(\%)$} \\
\hline Girls & 24 & $13(54.2)$ & 60 & $24(40.0)$ & 71 & $34(47.9)$ & 31 & $14(45.2)$ \\
\hline Boys & 26 & $15(57.7)$ & 56 & $21(37.5)$ & 58 & $25(43.1)$ & 32 & $12(37.5)$ \\
\hline \multicolumn{9}{|c|}{ Screen-time, h/week ${ }^{\mathrm{e}}$, mean (SD) } \\
\hline Girls & 25 & $9.9(10.2)$ & 61 & $6.2(5.0)$ & 70 & $6.6(4.9)$ & 31 & $7.4(4.9)$ \\
\hline Boys & 26 & $5.2(4.8)$ & 56 & $7.3(7.4)$ & 57 & $6.3(5.1)$ & 31 & $10.2(8.4)$ \\
\hline \multicolumn{9}{|c|}{ Time spent with books h/week ${ }^{\mathrm{f}}$, mean (SD) } \\
\hline Girls & 25 & $8.1(5.9)$ & 61 & $7.4(5.6)$ & 70 & $6.0(3.6)$ & 31 & $6.1(3.5)$ \\
\hline Boys & 26 & $7.1(5.1)$ & 56 & $7.2(4.0)$ & 57 & $6.0(4.3)$ & 31 & $6.3(5.4)$ \\
\hline \multicolumn{9}{|c|}{ Sleep quality $(\mathrm{CSHQ})^{\mathrm{g}}$, mean (SD) } \\
\hline Girls & 22 & $45.3(6.1)$ & 58 & $44.7(5.6)$ & 63 & $45.2(5.2)$ & 31 & $46.1(4.8)$ \\
\hline Boys & 25 & 48.0 (7.6) & 50 & $45.8(6.1)$ & 53 & $45.4(7.8)$ & 29 & $44.2(6.1)$ \\
\hline \multicolumn{9}{|c|}{ PA = physical activity; $h=$ hours; $S D=$ standard deviation. Details of groups $1-4$ see methods. } \\
\hline \multicolumn{9}{|c|}{ a KINDL questionnaire, higher values indicate higher health-related quality of life } \\
\hline \multicolumn{9}{|c|}{ b Strengths and Difficulties Questionnaire (SDQ), higher values indicate more emotional and behavioral difficulties } \\
\hline \multicolumn{9}{|c|}{ c Items answered with 'physical active' outweighing items answered with 'physical inactive'; Score from - 7 to + 7} \\
\hline \multicolumn{9}{|c|}{ d at least three of five categories were rated with infrequent physical active } \\
\hline \multicolumn{9}{|c|}{$\begin{array}{l}\text { e Including time spent with TV/DVD (also via computer/smartphone), time spent with computer games/game consoles (also via smartphone), time spent } \\
\text { with other use of internet/computer (also via smartphone) }\end{array}$} \\
\hline \multicolumn{9}{|c|}{ f either read by themselves or read to them by someone else } \\
\hline
\end{tabular}


Table 3

Associations between the COVID-19 pandemic and several health related outcomes in $n=362$ children in first grade of school, adjusted for age, year of sc educational attainment mother** using linear/logistic regression models, stratified by gender (boys vs. girls)

\begin{tabular}{|c|c|c|c|c|c|c|c|c|c|c|c|c|c|}
\hline & & \multicolumn{2}{|c|}{$\begin{array}{l}\text { Health related } \\
\text { quality of life } \\
(\text { KINDL) }\end{array}$} & \multicolumn{2}{|c|}{$\begin{array}{l}\text { Emotional and } \\
\text { behavioural } \\
\text { difficulties (SDQ) }\end{array}$} & \multicolumn{2}{|l|}{$\begin{array}{l}\text { PA-Score } \\
(-7 \text { to }+7)^{c}\end{array}$} & \multicolumn{2}{|c|}{$\begin{array}{l}\text { Physical } \\
\text { Inactive }^{d}\end{array}$} & \multicolumn{2}{|c|}{$\begin{array}{l}\text { Screen-time } \\
\text { (hours/week) }^{\mathrm{e}}\end{array}$} & \multicolumn{2}{|c|}{$\begin{array}{l}\text { Time spent with } \\
\text { books } \\
\text { (hours/week) }^{f}\end{array}$} \\
\hline & & $\begin{array}{l}\text { Differences } \\
\text { in Means }\end{array}$ & $\begin{array}{l}\mathrm{p}- \\
\text { value }\end{array}$ & $\begin{array}{l}\text { Differences } \\
\text { in Means }\end{array}$ & $\begin{array}{l}\mathrm{p}- \\
\text { value }\end{array}$ & $\begin{array}{l}\text { Differences } \\
\text { in Means }\end{array}$ & $\begin{array}{l}\mathrm{p}- \\
\text { value }\end{array}$ & $\begin{array}{l}\text { Odds } \\
\text { Ratio }\end{array}$ & $\begin{array}{l}\mathrm{p}- \\
\text { value }\end{array}$ & $\begin{array}{l}\text { Differences } \\
\text { in Means }\end{array}$ & $\begin{array}{l}\text { p- } \\
\text { value }\end{array}$ & $\begin{array}{l}\text { Differences } \\
\text { in Means }\end{array}$ & $\begin{array}{l}\mathrm{p} \text { - } \\
\text { value }\end{array}$ \\
\hline & & $(95 \% \mathrm{Cl})$ & & $(95 \% \mathrm{Cl})$ & & $(95 \% \mathrm{Cl})$ & & $\begin{array}{l}(95 \% \\
\mathrm{Cl})\end{array}$ & & $(95 \% \mathrm{Cl})$ & & $(95 \% \mathrm{Cl})$ & \\
\hline \multirow[t]{2}{*}{$\begin{array}{l}\text { COVID-19 } \\
\text { pand. }\end{array}$} & g & $\begin{array}{l}-5.5(-9.0, \\
-2.0)\end{array}$ & 0.002 & $\begin{array}{l}2.0(0.2 \\
3.8)\end{array}$ & 0.03 & $\begin{array}{l}0.3(-0.9 \\
1.5)\end{array}$ & 0.6 & $\begin{array}{l}0.9 \\
(0.4 \\
2.1)\end{array}$ & 0.8 & $\begin{array}{l}0.6(-1.8 \\
2.9)\end{array}$ & 0.6 & $\begin{array}{l}-0.03(-2.0 \\
1.9)\end{array}$ & 0.98 \\
\hline & b & $\begin{array}{l}-1.0(-5.2 \\
3.2)\end{array}$ & 0.6 & $\begin{array}{l}\text { 1.3 (-1.1, } \\
3.7)\end{array}$ & 0.3 & $\begin{array}{l}0.6(-0.7 \\
1.9)\end{array}$ & 0.4 & $\begin{array}{l}0.7 \\
(0.3 \\
1.9)\end{array}$ & 0.5 & $\begin{array}{l}3.5(0.6 \\
6.4)\end{array}$ & 0.02 & $\begin{array}{l}0.5(-1.5 \\
2.5)\end{array}$ & 0.6 \\
\hline \multirow[t]{2}{*}{$\begin{array}{l}\mathrm{N} \\
\text { observations }\end{array}$} & g & $N=178$ & & $N=190$ & & $N=189$ & & $\begin{array}{l}N= \\
186\end{array}$ & & $N=187$ & & $N=187$ & \\
\hline & b & $N=160$ & & $N=170$ & & $N=170$ & & $\begin{array}{l}N= \\
170\end{array}$ & & $N=168$ & & $N=168$ & \\
\hline
\end{tabular}

$\mathbf{g}=$ girls; $\mathbf{b}$ = boys; vs = versus; $\mathrm{Cl}=$ confidence interval; $\mathrm{PA}=$ physical activity .

${ }^{a}$ KINDL questionnaire, higher values indicate higher health-related quality of life

b Strengths and Difficulties Questionnaire (SDQ), higher values indicate more emotional and behavioral difficulties

c Items answered with 'physical active' outweighing items answered with 'physical inactive'; Score from - 7 to +7

${ }^{\mathrm{d}}$ logistic regression model, modelling the probability for being physically inactive vs. physical active

e Including time spent with TV/DVD (also via computer/smartphone), time spent with computer games/game consoles (also via smartphone), time spent wit internet/computer (also via smartphone)

$\mathrm{f}$ either read by themselves or read to them by someone else

${ }^{g}$ Child Sleep Habits Questionnaire (CSHQ), higher values indicate more sleep problems

*09/2018 or $09 / 2019$

**duration of school education: $\leq 9$ years, $10-11$ years, or $\geq 12$ years

\section{Figures}




\begin{tabular}{|c|c|}
\hline Age of 6 & Age of 7 \\
April 2018-May 2019 & April 2019-May 2020 \\
Questionnaires came back until Aug 19 & Questionnaires came back until Jul 20 \\
\hline
\end{tabular}

\begin{tabular}{|c|c|}
\hline Follow-up before first lockdown in Germany & $\begin{array}{c}\text { Follow-up after first } \\
\text { lockdown in Germany } \\
\text { (during pandemic) }\end{array}$ \\
$13^{\text {th }}$ Sep $18-15^{\text {th }}$ Mar 2020 & $16^{\text {th }}$ Mar 20-27 $27^{\text {th }}$ Jul 20 \\
\hline
\end{tabular}

Date when questionnaires were filled out as criteria for different groups of first-grader

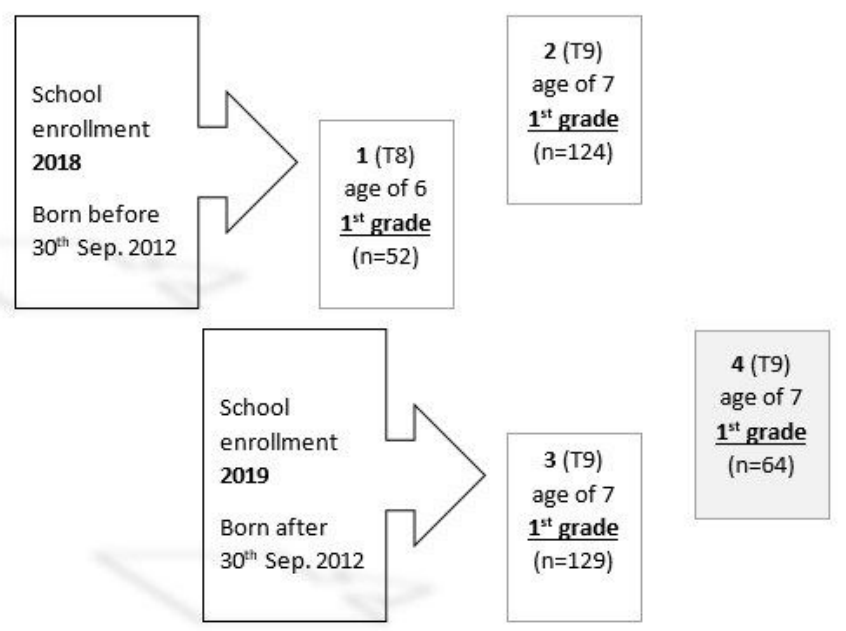

Figure 1

Study sample of first-graders was derived from longitudinal SPATZ cohort (birth cohort recruitment took place from April 2012 to May 2013). Four different groups of first-graders were derived. 